\title{
Correlation between length of little finger and occlusal vertical dimension in Indonesian subraces
}

\author{
Eni Rahmi ${ }^{*}$, Hidayati ${ }^{2}$, Kosno Suprianto ${ }^{3}$, Cytha Nilam Chairani ${ }^{1}$, Siti Rahmadita ${ }^{1}$, \\ Mia Ladiovina ${ }^{1}$ \\ 'Department of Prosthodontics, Faculty of Dentistry Andalas University, Indonesia \\ ${ }^{2}$ Department of Dental Public Health, Faculty of Dentistry Andalas University, Indonesia \\ ${ }^{3}$ Department of Periodontics, Faculty of Dentistry Gadjah Mada University, Indonesia
}

\begin{abstract}
Introduction: The correct determination of proper occlusal vertical dimension (OVD) is an important step that must be con-cerned by the dentist in dental treatment procedures. There are varieties of the method to establish OVD such as anthropo-metric measurements of OVD and length of little finger (LLF). This study was aimed to analyse the correlation between the occlusal vertical dimension with the length of little finger in Indonesian subraces such as Deutro-Malay, Proto-Malay, and In-donesian Chinese subraces. Methods: A cross-sectional study was conducted on 336 dentate subjects comprising of 168 males and 168 females with an age range between 20-35 years old with no little finger deformity. The sampling technique used was consecutive sampling. Anthropometric measurement of OVD and LLF were recorded clinically using a digital vernier calliper. Correlation between OVD and LLF was analysed using the Pearson correlation. Results: Result of the statistical test showed that the OVD was significantly $(p=0.000)$ and positively correlated with LLF, and showed a strong correlation ( $r=0.779)$ in Indonesian subraces. Conclusion: There is a correlation between occlusal vertical dimension measurement and the length of little finger in Indonesian subraces.
\end{abstract}

Keywords: Indonesian subraces, length of little finger, occlusal vertical dimension.

p-ISSN: 1979-0201; e-ISSN: 2549-6212; Available from: http://jurnal.unpad.ac.id/pid/article/view/24966

DOI: $10.24198 / \mathrm{pjd}$.vol32no1.24966

Submission: Dec 04, 2019; Accepted: Mar 3, 2020; Published online: Mar 31, 2020

\section{INTRODUCTION}

Occlusal vertical dimension (OVD) is vertical relationship between maxilla and mandible that is considered asone of the influential aspects in stomatognathic system. This dimension determination is necessary in dental care, such as treatment of edentulous with fixed partial denture or removable denture. That stage significantly cannot be neglected thus optimum and aesthetic functions can be accomplished. ${ }^{1,2}$ Occlusal Vertical Dimension value stays constant during

"Corresponding author: Eni Rahmi, Department of Prosthodontics, Faculty of Dentistry Andalas University, Jalan Perintis Kemerdekaan No. 77, Padang, West Sumatera, Indonesia, 25171. Phone: +628113579513; Email: enirahmi@yahoo.com 
human lifetime. Vertical dimension change may be induced by dental loss, attrition, caries and some restorations which are unable to maintain the proper clinical crown height, and denture which fail to restore the vertical dimension. This alteration leads to disturbed masticatory system physiology, despite certain researchers stated that patients can adapt to the change..$^{1-3}$

Dentists are responsible in determining the correct OVD for specific dental care. In order to obtain accurate output, it is suggested to be calculated in various methods. Conventional method such as two dot technique is the one generally applied by Indonesian dentists. However in its execution, OVD determination is not quite simple moreover on elderly patients who have suffered total or partial edentulous for reasonably long time. Besides, there are numerous factors responsible to ambiguity in its measurement and calculation, such as complication in measuring facial skin due to uneasy landmark point definition, and present psychological and pathological alterations. $^{3}$

Anthropometry method is one of technique in OVD determination. Da Vinci and McGee declared that OVD correlates with many anthropometrical measurements. Accordingly, lots of body and facial measurements are recommended in OVD selection, including face and one third of lower face proportion. ${ }^{8}$ Yet there are still no deliberations of more accurate method compared to others. Hence, series of measurement methods are needed to be carried out as comparison to acquire the most accurate result. ${ }^{4}$

There are studies concerning comparison between fingers anthropometry measurement and OVD determination, namely thumb length ${ }^{5}$, index finger, little finger and space between thumb and index finger tip. ${ }^{4,6}$ Based on these observations, some presented that little finger measurement is considered succeeded in fulfilling the criteria thus can be selected for selecting OVD. Previous study by Bhandari, et al and Kalra, et al stated that little finger measurement result is nearly similar to OVD value hence can be applied to predict OVD value. ${ }^{7,8}$ This method is reliable, simple, innovative, non-invasive, economical, and does not require equipment that are difficult to provide. ${ }^{4,6-8}$

Method of OVD determination by little finger anthropometric measurement has plentiful advantages; however the related researches are still limited. Majority were conducted on India population. It will be most likely that study on different race would lead to diverse results as well. In Indonesia, fingers anthropometry measurements are still rarely found. Saragih investigated index and little finger length and space between thumb and index finger of Batak Toba tribe. ${ }^{9}$ Therefore, the researchers have been interested in this more advance research of little finger measurement to be conducted in Indonesia by connecting link between little finger length and OVD.

Indonesia has tribe diversity that can be classified into 3 groups, namely Deutro-malay sub race, Proto-malay sub race and Indonesian Chinese ethnicity which is included to Asiatic Mongoloid sub race. According to Board of Statistics Center of Padang city in 2010, population reached 833,562 people. Padang citizens consist of tribes representing sub-races in Indonesia, such as Deutro-malay sub race (Minangkabau, Jawa, Malays, Aceh, Betawi, and Sunda tribes), Protomalay sub race (Batak, Nias, and Mentawai tribes), and Indonesian Chinese ethnicity. These tribes spread throughout the city with representative total number. ${ }^{10}$ This study was aimed to analyse the correlation between the occlusal vertical dimension with the length of little finger in Indonesian subraces such as Deutro-Malay, ProtoMalay, and In-donesian Chinese subraces.

\section{METHODS}

A cross sectional study was conducted towards the populations which included the Deutro Malays sub race, Proto Malays sub race and Indonesian Chinese ethnicity of Padang City citizens who were identified as native descents for minimum of 2 generations with age range of 20-35 years old. The sampling method was consecutive sampling. The observation was undertaken in concentrated regions with most population number of selected tribe in Padang City. The study was conducted after ethical clearance from the Institutional Ethical committee was obtained.

Subjects were given instructions regarding the research, afterwards an interview about tribe and lineage to identify racial authenticity and clinical examination were conducted. Inclusion criteria were Deutro-malay sub race, 
Proto-malay sub race, and Indonesian Chinese ethnicity. (minimum 2 pure generations); 20-35 years old; have at least 28 fully erupted teeth with a definite centric occlusion; and Class I jaw relationship. Exclusion criterias included: bone deformity especially little finger, malocclusion, missing teeth, history of trauma, orthodontic and prosthodontic treatment. Those who fit the inclusion criteria were asked to sign the informed consent. The selected research subjects were performed measurement of OVD distance by two dot technique (subnation to gnathion point) and right length of little finger from the tip to base or the furthest point of metacarpophalangeal (MCP) crease when the hand is stretched out. These two measurements were carried out by digital vernier caliper (Figure 1). Data of observation result were tested statistically using Pearson Correlation.

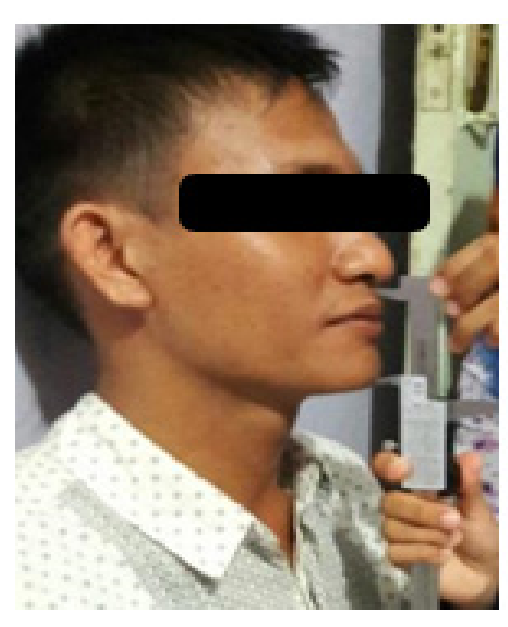

A

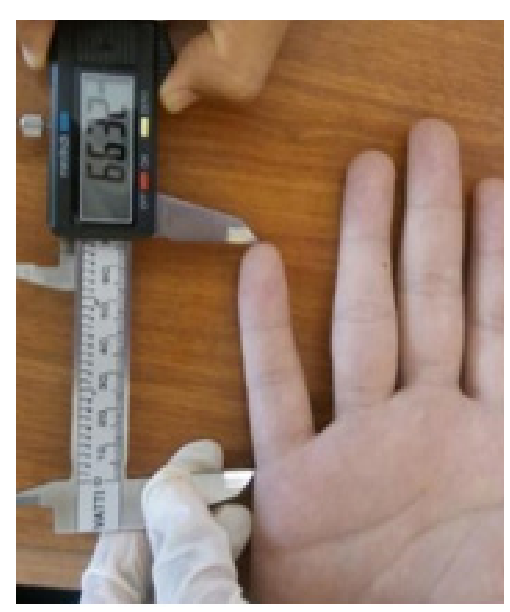

B

Figure 1. A. Occlusal vertical dimension measurement (OVD); B. Length of little finger (LLF)

\section{RESULTS}

Data of research output in form of OVD and LLF measurement results were obtained by samples who met the criteria as many as 336 people. The observationwasundertakenonsamplesrepresenting
Deutro-malay sub race, Proto-malay sub race and Indonesian Chinese ethnicity who reside in Padang City. Univariate analysis aims for describing statistical result of OVD and LLF measurement of research samples. Data was presented descriptively within tables as followed below:

Table 1. Occlusal vertical dimension (OVD) and length of little finger (LLF) measurement results

\begin{tabular}{cccccc}
\hline Measurement $(\mathrm{mm})$ & $\mathrm{n}$ & Mean $(\mathrm{mm})$ & Minimum $(\mathrm{mm})$ & Maximum $(\mathrm{mm})$ & $\mathrm{SD}(\mathrm{mm})$ \\
\hline OVD & 336 & 63.36 & 52.31 & 79.32 & 4.76 \\
LLF & 336 & 60.98 & 49.26 & 75.96 & 4.68 \\
\hline
\end{tabular}

Based on table 1, OVD mean value obtained was $63.36 \mathrm{~mm}$ with range of $52.31-79.32 \mathrm{~mm} \pm 4.76$ $\mathrm{mm}$. On the other hand, LLF mean value was 60.9 $\mathrm{mm}$ with range of $49.26-75.96 \mathrm{~mm} \pm 4.68 \mathrm{~mm}$.

Table 2. Occlusal vertical dimension (OVD) and length of little finger (LLF) measurement in Deutro-malay sub race, Protromalay sub race and Indonesian Chinese ethnicity

\begin{tabular}{lcccccc}
\hline \multicolumn{1}{c}{$\mathrm{n}$} & Measurement $(\mathrm{mm})$ & $\mathrm{n}$ & Mean $(\mathrm{mm})$ & Minimum $(\mathrm{mm})$ & Maximum $(\mathrm{mm})$ & SD $(\mathrm{mm})$ \\
\hline \multirow{2}{*}{ Deutro-Malay } & OVD & 112 & 62.43 & 52.31 & 73.11 & 4.13 \\
& LLF & 112 & 60.68 & 49.90 & 72.78 & 4.73 \\
Proto-Malay & OVD & 112 & 62.75 & 52.87 & 75.46 & 4.62 \\
& LLF & 112 & 60.12 & 50.27 & 71.72 & 4.29 \\
Indonesian Chinese & OVD & 112 & 64.89 & 53.95 & 79.32 & 5.18 \\
& LLF & 112 & 62.12 & 49.26 & 75.96 & 4.82 \\
\hline
\end{tabular}


According to Table 2, OVD mean value by Deutro-malay sub race sample $(62.43 \pm 4.13 \mathrm{~mm}$, with range of $52.31-73.11 \mathrm{~mm})$, Protro-malay sub race sample $(62.75 \pm 4.62 \mathrm{~mm}$, with range of 52.87-75.46 mm), and Indonesian Chinese ethnicity sample $(64.89 \pm 5.18 \mathrm{~mm}$, with range of 53.95-79.32 $\mathrm{mm}$ ). The same result was found, the LLF mean value of Deutro-malay sub race sample $(60.68 \pm 4.73 \mathrm{~mm}$, with range of $49.90-72.78 \mathrm{~mm})$, Protro-malay sub race sample $(60.12 \pm 4.29 \mathrm{~mm}$, with range of 50.27-71.72 $\mathrm{mm}$ ), and Indonesian Chinese ethnicity sample $(62.12 \pm 4.82 \mathrm{~mm}$, with range of 49.26-75.96 mm).

Bivariate analysis was performed to define relationship between two variables namely dependent (OVD measurement result) and independent variable (LLF measurement result).

Table 3. Correlation between OVD and LLF measurement results

\begin{tabular}{cccc}
\hline & $\mathrm{N}$ & Correlation coefficient & LLT \\
\hline \multirow{2}{*}{ OVD } & \multirow{2}{*}{336} & $\mathrm{R}$ & 0.779 \\
& & $\mathrm{P}$ & 0.000 \\
\hline
\end{tabular}

Based on Table 3, OVD and LLF measurement result showed $r$ value of 0.779 . It indicated correlation between the two latter outputs, OVD and LLF measurement result strongly along with a positive pattern. Statistical test outcome figured that regarding correlation between OVD and LLF measurement result the $p$ value achieved was 0.000 , which portrayed significance.

Table 4. Correlation between OVD and LLF measurement results in Deutro-malay sub race, Proto-malay subrace and Indonesian Chinese ethnicity

\begin{tabular}{lcccc}
\hline \multicolumn{1}{c}{ Sub race } & & $\mathrm{n}$ & $\begin{array}{c}\text { Correlation } \\
\text { coefficient }\end{array}$ & LLF \\
\hline Deutro-Malay & OVD & 112 & $\mathrm{R}$ & 0.754 \\
& & 112 & $\mathrm{R}$ & 0.000 \\
Proto-Malay & OVD & 112 & $\mathrm{R}$ & 0.707 \\
& & 112 & $\mathrm{R}$ & 0.000 \\
Indonesian & OVD & 112 & $\mathrm{R}$ & 0.852 \\
Chinese & & 112 & $\mathrm{P}$ & 0.000 \\
\hline
\end{tabular}

Table 4 presented OVD and LLF measurement result among Deutro-malay sub race, Proto-malay sub race, and Indonesian Chinese ethnicity. These results of data analysis stated that correlation between OVD and LLF measurement result was strong and positive-patterned. Statistical test output concerning OVD and LLF measurement result correlation presenting $p$ value of 0.000 indicated significance. It can be observed that data analysis outcome was compatible to hypothesis that accounted correlation between OVD and LLF measurement result among Deutro-malay sub race, Protro-malay sub race and Indonesian Chinese ethnicity in Padang City.

\section{DISCUSSION}

The proper OVD determination is considered as one of the most prominent factors for dentists in specific dental care clinical procedure. Numerous methods are suggested in calculating OVD duly, since output by single method may contradict with others. It rendered issues in OVD establishment. Study of comparison between OVD and anthropometric parameter measurement such as length of finger measurement result was conducted to solve the obstacle in defining OVD remembering that the technique is adaptable as comparison method towards other options.

In this research, the selected OVD measurement method was two dot technique, and it was compared with little measurement result of finger length anthropometrical parameter. The measurement performed was merely on right little finger. This preference is believed not going to induce deviation due to previous observations claimed that physiologically human body maintains its symmetry. Identical to study by Danborno, it was found that there is no difference between two hands fingers length. ${ }^{12}$ Calculation of OVD and LLF was undertaken on individuals with normal growth pattern and proportional body parts. The term of "proportions forecasting" introduced by Da Vinci declared that there have been various observations of face and other body parts related to OVD. ${ }^{8}$ This research aftermath was proven supported the Leonardo Da Vinci's theory.

This research outcome disclosed that OVD and LLF measurement possessed significantly desired value similarity among Proto Malays sub-race, Deutro-malay sub race and Indonesian Chinese ethnicity. The mean value of OVD in Deutro-malay sub race was found to be $62,75 \mathrm{~mm}$, in Protromalay sub racewas $62,43 \mathrm{~mm}$, and in Indonesian Chinese ethnicity was $64,89 \mathrm{~mm}$. Similarly, the mean value of LLF in Deutro-malay sub race was 
$60.68 \mathrm{~mm}$, in Protro-malay sub racewas 60.12 $\mathrm{mm}$ and in Indonesian Chinese ethnicity was $62,12 \mathrm{~mm}$. This study also revealed that OVD was significantly and positively correlated with LLF among Deutro-malay sub race, Protro-malay sub raceand Indonesian Chinese ethnicity $(r=0.779)$. This correlation means the greater OVD value, the longer little finger length tend to be. Statistical test result indicated correlation between OVD and LLF measurement output with $p$ value of 0.000 that showed significance.

It is identical to previous related studies abroad, such as in India by Bhandari, et $\mathrm{al}^{7}$ that claimed OVD $(61.09 \mathrm{~mm})$ was found to be almost equal to the LLF $(60.57 \mathrm{~mm})$, and there was significantly and positively correlation between OVD and LLF in Indian population $(r=0.840)$. The result of this study also showed that OVD calculation was significant towards LLF of male and female. Other reference concerning OVD measurement significance on finger anthropometrical parameter was by Kalra $D$ et $\mathrm{al}^{8}$. This study also reported that OVD was significantly and positively correlated with all parameters studied such as length of middle finger, length of little finger, and distance from tip of midlle finger to tip of thumb. Findings by Miran et $\mathrm{al}^{11}$ among Kurdish population pointed that OVD and LLF measurement was significant among their male and female. In Indonesia solely, the alike discovery was reported by Elisabeth Saragih about OVD distance in Protro-malay sub raceof Batak Toba tribe.

There are factors influencing OVD during growth and development, such as: ramus of mandible growth, gonial angle of mandible, dental eruption, and craniofacial. OVD gains its maximum size if the growth and development process has been complete. Commonly, the latter process takes place during age range of 12-20 years old for male and 10-18 years old for female. ${ }^{13}$

Radiographic of wrist has been chosen for dentofacial structures growth examination as skeletal age indicator in several phases in postnatal development. Ossification series determination from carpal, metacarpal and phalangeal bone can be undertaken towards mostly healthy children, both male and female. Female post-puberty phase takes place during 15-17 years old whereas male is 17-19 years old. Entire carpal, metacarpal and phalangeal bones in this phase have developed completely. ${ }^{14}$ Thus, measurement of OVD and LLF anthropometrical parameter are undertaken during age range of 20-35 years old when OVD is considered not going to alters much and little finger bones have been developed completely.

\section{CONCLUSION}

There is a correlation between occlusal vertical dimension measurement and the length of little finger in Indonesian subraces, thus, anthropometric parameter measurement of the length of little finger can be used in the determination of occlusal vertical dimension.

\section{REFERENCES}

1. Basker RM, Davenport JC, Thomason JM. Prosthetic treatment of the edentulous patient $5^{\text {th }}$ Ed. New Delhi, India: Blackwell Publishing Ltd; 2011. p. 68, 151.

2. Zarb GA, Bolender CL, Eckert SE, Jacob RF, Fenton AH, Mericske-Stern R. Prosthodontic treatment for edentulous patient: complete dentures and implant supported prostheses $13^{\text {th }}$ ed. St Louis, MO: Mosby; 2013. p. 274-82.

3. Sarandha, Hussain Z, Uthkarsh. Textbook of complete denture prosthodontics. $1^{\text {st }}$ ed. New Delhi, India: Jaypee Brothers Medical Publishers (P) Ltd; 2007. p. 80-5.

4. Rupesh PL, Subhas S, Salagundi B, KM Regish, Poonacha VUP et al. Leonardo da vinci's divine proportion in establishing vertical dimension. J Ulti Dent Res. 2012;1(2):1-7.

5. Basnet BB, Parajuli PK, Singh RK, Suwal $P$, Shrestha P, Baral D. An anthropometric study to evaluate the correlation between the occlusal vertical dimension and length of the thumb. Clin Cosmet Investig Dent. 2015;7:339. DOI: $10.2147 / \mathrm{CCIDE} .575872$.

6. Ladda R, Bhandari AJ, Kasat VO, Angadi GS. A new technique to determine vertical dimension of occlusion from anthropometric measurements of fingers. Indian J Dent Res. 2013;24(3):316-20. DOI: 10.4103/09709290.117993.

7. Bhandari AJ, Ladda R, Bhandari AJ. Correlation between vertical dimension of occlusion and lenght of little finger. Pravara Med Rev. 2012; 4(4): $0-4$ 
8. Kalra D, Kalra A, Goel S. Determination of vertical dimension of occlusion from anthropometric measurement of fingers an in vivo study. Int J Enhanced Res Med Dent Care. 2015;2(2):10-15.

9. Saragih E. Nilai konversi jarak DVO dengan panjang jari tangan kanan pada suku batak toba [minor thesis]. Medan: North Sumatra University; 2015.

10. Board of Statistics Center of Padang City. Sensus Penduduk tahun 2010.

11. Miran FA, Mahmood KA. The correlation between the right little finger, eye - ear distance and vertical dimension of occlusion among students of faculty of medical sciences in university of sulaymani. IOSR J Dent Med Sci.2015;14(12):69-73. DOI: 10.9790/0853141216973

12. Danborno B, Adebisi S, Adelaiye A, Ojo $S$. Estimation of height and weight from the lengths of second and fourth digits in Nigerians. Int J Forens Sci 2009;3(2):1-4.

13. McDonald A. Dentistry for the Child and Adolescent. 9 $^{\text {th }}$ ed. St. Louis: Mosby-Elsevier; 2011. p. 513.

14. Gilsanz V, Ratib O. Hand Bone Age: A Digital Atlas of Skeletal Maturity. Berlin: Springer Science \& Business Media; 2005. p. 16-17. 